\title{
Synthesis, Characterization and Antimicrobial studies of N-cyclohexyl acrylamide and 7-methacryloyloxy-4-methyl coumarin copolymers
}

\author{
S. Anbarasan ${ }^{1}$, R. Chitra ${ }^{2}$, E.Kayalvizhy ${ }^{3}$ and P.Pazhanisamy ${ }^{4 *}$ \\ ${ }^{1}$ Department of Chemistry, Thiru. A.Govindasamy Govt.Arts College, Affiliated to Thiruvalluvar \\ University, Tindivanum,-604307, TamilNadu, India \\ ${ }^{2}$ Department of Chemistry, Guru Nanak College, Affiliated to University of Madras, Chennai \\ -600 042, Tamil Nadu, India. \\ ${ }^{3}$ Department of Chemistry, PSGR Krishnammal College for Women, Coimbatore-641004, \\ Affiliated to Bharathiar University, India. \\ ${ }^{4}$ Department of Chemistry, Sir Theagaraya College, Affiliated to University of Madras, \\ Chennai-600 021, Tamil Nadu, India. \\ E-mail: p_pazhanisamy@yahoo.com
}

\begin{abstract}
A series of copolymers of $N$-cyclohexylacrylamide (NCA) and 7-methacryloyloxy-4-methyl coumarin (MACU) were prepared by free radical polymerization using AIBN as initiator in $D M F$. The copolymer compositions were determined by ${ }^{l} H N M R$ analysis. The reactivity ratios were determined by linear methods like Finemann-Ross and Kelen-Tudos methods. The value of $r_{1}$ is less than $r_{2}$. So MACU is found to have higher reactivity than NCA. Mean sequence lengths of copolymers were calculated from $r 1$ and $r 2$ values. The product of $r_{1} . r_{2}=1.1$, which is greater than 1 indicates that the copolymers are at random distribution of monomeric unit in the copolymer chain. Thermal studies indicates that the $T_{g}$ values are higher than the homopolymers of NCA. Antimicrobial studies showed that the copolymers are active against both Bacteria and fungi. However, these copolymers showed excellent antibacterial activity.
\end{abstract}

Keywords: N-cyclohexylacrylamide, 7-methacryloyloxy-4-methyl coumarin, mean sequence length, reactivity ratios, antibacterial activity.

\section{Introduction}

Antimicrobial properties of polymers has become one of the pioneer research area. Antimicrobial polymers are found to have various applications in day today life[1,2]. In our previous work, $\mathrm{N}$ - cyclohexylacrylamide was copolymerized with 8-quinolinyl acrylate[3], 2,4-Dichlorophenylmethacrylate[4] , 2,4-Dichlorophenylacrylate[5], 7-Acryloyloxy-4-methyl coumarin[6]. Copolymers of different feed ratio were prepared and characterized by ${ }^{1} \mathrm{H}-\mathrm{NMR}$ spectroscopic technique. Standard methods were used to determine Reactivity ratios, mean sequence lengths and Antimicrobial activities were determined.

In the current work, copolymers of N-cyclohexylacrylamide(NCA) and 7-methacryloyloxy4-methyl coumarin(MACU) were prepared in different feed ratio by free radical polymerization technique. The copolymers prepared in different feed ratios were characterized and copolymer composition was determined by ${ }^{1} \mathrm{H}-\mathrm{NMR}$ spectroscopy. Reactivity ratios were determined by standard methods like Finemann-Ross[7], Kelen-Tudos[8] and ext.KelenTudos[9] methods. Antibacterial and antifungal studies were carried out by well diffusion method. 


\section{Experimental}

\section{Preparation of N-cyclohexylacrylamide(NCA)}

Cyclohexanol and acrylonitrile[10 ]were used to prepare the monomer $\mathrm{N}$ cyclohexylacrylamide. The product was recrystallized in dry benzene. Yield of the reaction was found to be $87 \%$ and the m.pt of white crystals $115^{\circ} \mathrm{C}$. The monomer was characterized by ${ }^{1} \mathrm{H}-\mathrm{NMR}$ and ${ }^{13} \mathrm{C}-\mathrm{NMR}$.

\section{Preparation of 7-methacryloyloxy-4-methylcoumarin (MACU)}

7-methacryloyloxy-4-methyl coumarin (MACU) comonomer was prepared by esterfiation of 7-hydroxy-4-methyl coumarin and Methacryloyl chloride.Methacryloyl chloride has to be prepared freshly by reacting methacrylic acid with benzoyl chloride.Absolute ethanol $(400 \mathrm{~mL})$ and $\mathrm{NaOH}(0.2 \mathrm{~mol})$ were added to a three-necked flask that was equipped with stirrer, condenser and thermometer. The flask was placed in a water bath and the contents were stirred until all the $\mathrm{NaOH}$ was dissolved. Then, 7-hydroxy-4-methylcoumarin $(0.2 \mathrm{~mol})$ was added to the reaction mixture, heated to room temp. and then cooled to $0-5^{\circ} \mathrm{C}$. Freshly prepared methacryloyl chloride $(0.2 \mathrm{~mol})$ was added in drops to the reaction mixture and stirred for $90 \mathrm{~min}$. Then the mixture was poured in to a crushed-ice-water mixture, a white colored product was separated out. The product was filtered, washed thoroughly with cold water and recrystallized from methanol ${ }^{11}$.

\section{Copolymerization}

The copolymer NCA-co-MACU, i.e., of N-cyclohexylacrylamide (NCA) and 7methacryloyloxy-4-methyl coumarin (MACU) were prepared by free radical polymerizationtechnique in methanol/Water medium at $600^{\circ} \mathrm{C}$ using AIBN as an initiator ( Scheme-1).

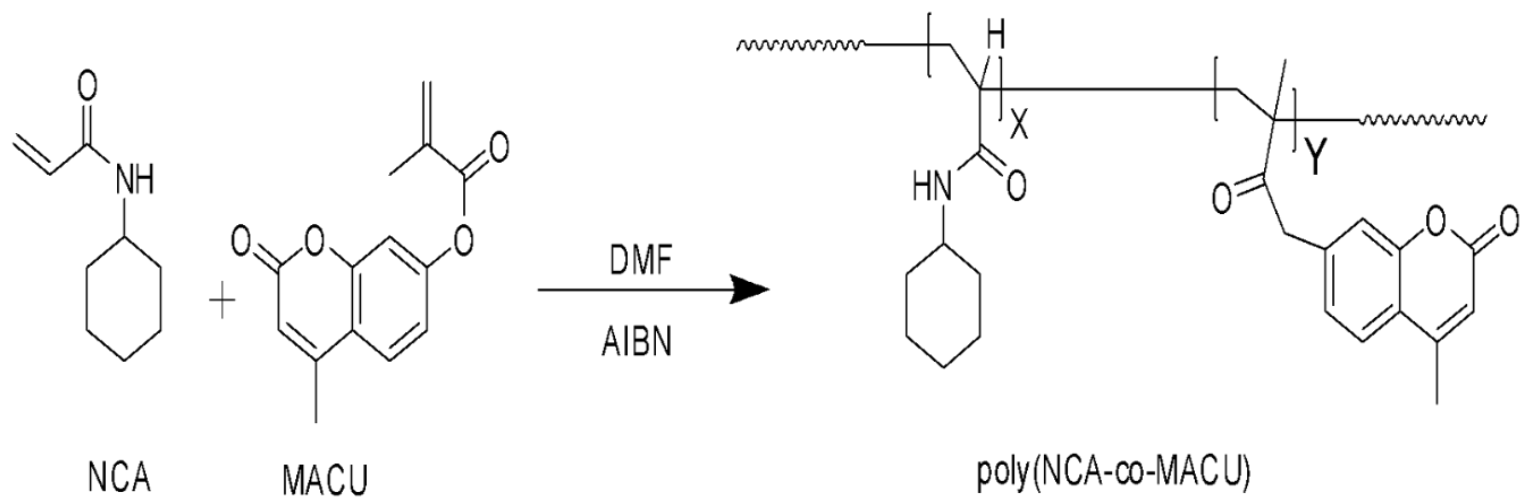

\section{Scheme 1: Copolymerization of NCA and MACU}

\section{Characterization of Copolymer spectra of Poly(NCA-co-MACU)}

${ }^{1} \mathrm{H}-\mathrm{NMR}$ spectral technique was used to characterize the copolymers . (Figure.1). The peaks observed were assigned for functional froups as follows : at 1.14-2.96 ppm for cyclohexyl $\mathrm{CH}_{2}$ group , at 3.68ppm for backbone $\mathrm{CH}_{2}$, at 7.07-8.01 ppm due to MACU aromatic protons. 


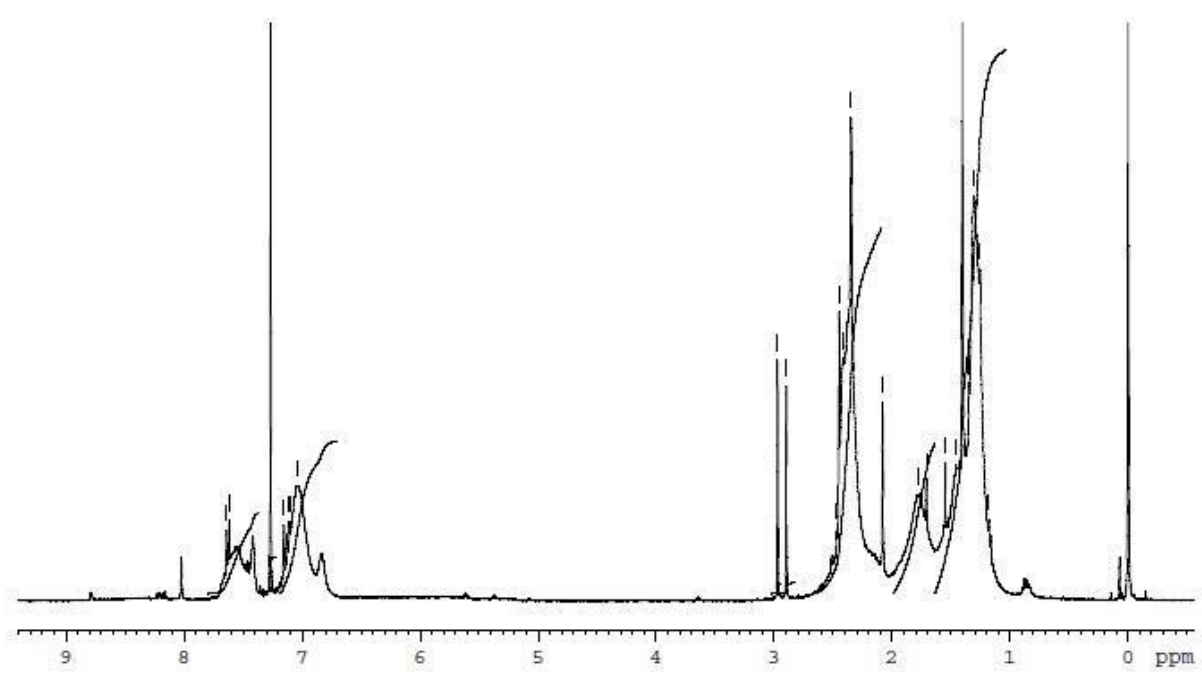

Figure 1 :'H-NMR spectraof copolymer (NCA-co-MACU)

\section{Determination of copolymer composition of Poly(NCA-co-MACU)}

${ }^{1} \mathrm{H}-\mathrm{NMR}$ spectral analysis was used to determine the copolymer composition of the copolymers prepared in different feed ratio. The Coumarin acrylate area was taken as standard to determine the copolymer composition. Resonance signal at 7.07-8.01 ppm corresponds to aromatic proton, and their integrated intensity of this peak is compared to the total intensities of all the peaks in the copolymer spectrum, which is a measure of their relative areas. The copolymer compositions can be obtained using

$$
\mathrm{X}_{\mathrm{MACu}}=\frac{15 \mathrm{~A} \text { (aryl) }}{3 \mathrm{~A}_{\text {total }}+3 \mathrm{~A} \text { (aryl] }}
$$

Where $\mathrm{X}=$ mole fraction and $\mathrm{A}=$ peak area. The copolymer composition curve is not sigmoidal which shows that there is no azeotropic copolymer composition. (Figure 2)

\section{Determination of Reactivity ratios of Poly(NCA-co-MACU)}

Fineman-Ross (FR ) and Kelen- Tudos (KT) methods were used to evaluate the reactivity ratios of monomer 1 (NCA) and monomer 2 (MACU). From the monomer feed ratios and copolymer compositions, the parameters of F-R,K-T and ext K-T were calculated, The values are tabulated in Table 1,2.The reactivity ratios for NCA $\left(\mathrm{r}_{1}\right)$ and $\mathrm{MACu}\left(\mathrm{r}_{2}\right)$ from the F-R plot(Figure 3) K-Tplot(Figure 4) and ext K-T plot(Figure 5) are given in Table 3. The value of $r_{1}$ is less than $r_{2}$. Therefore, MACU is highly reactive than NCA. The product of $r_{1}, r_{2}=$ 1.1 , which is greater than 1 shows that the copolymers are distributed randomly in copolymer chain[11-13].

\section{Determination of Mean sequence lengths of Poly(NCA-co-MACU)}

The mean sequence lengths of copolymers as inferred from Table 4, shows that the MACU units increases in a linear fashion in the polymer chain.

\section{Thermal studies of Poly(NCA-co-MACU)}

Thermal properties of copolymers were studied using TGA and DSC analysis. The results are shown in Figure. 6 and the values are given in Table-5. Copolymers are found to undergo three stage decomposition. Initial weight loss is associated with moisture content. Amide group undergoes partial degradation at stage-1, decarboxylation and/or other reactions of side-chain units at stage-2, main-chain degradation reactions and breakdown of the polymer backbone at stage-3. $\mathrm{T}_{\mathrm{g}}$ values are higher than the homopolymers of NCA. 


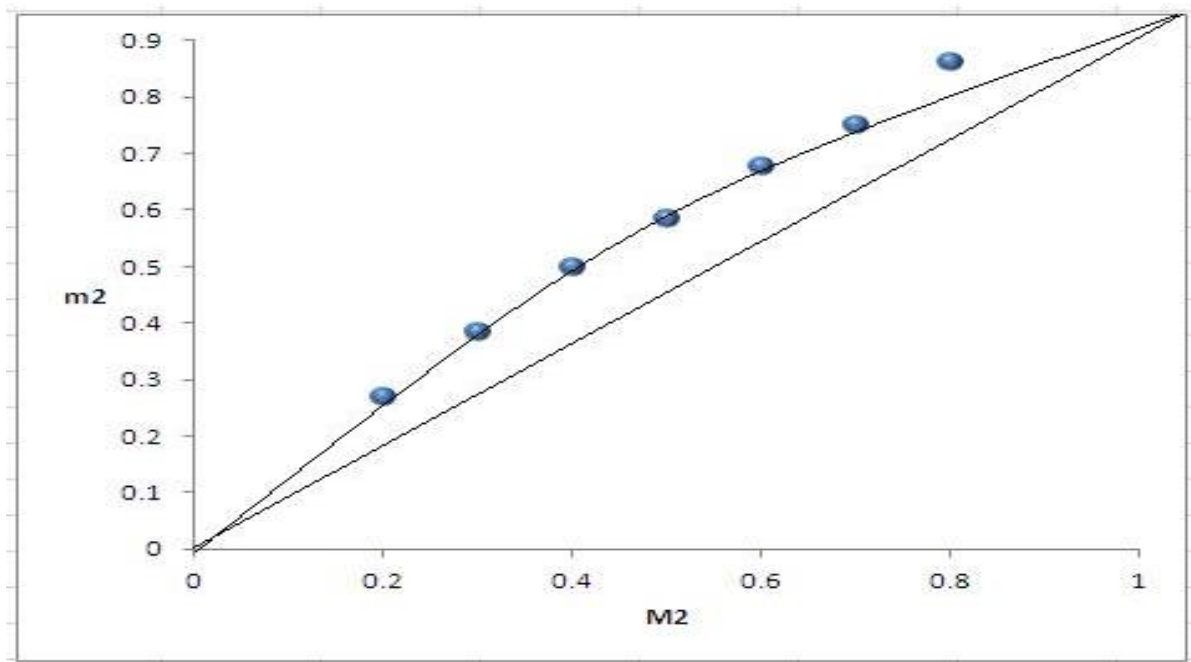

Figure 2: Copolymer composition curve of Poly(NCA-co-MACU)

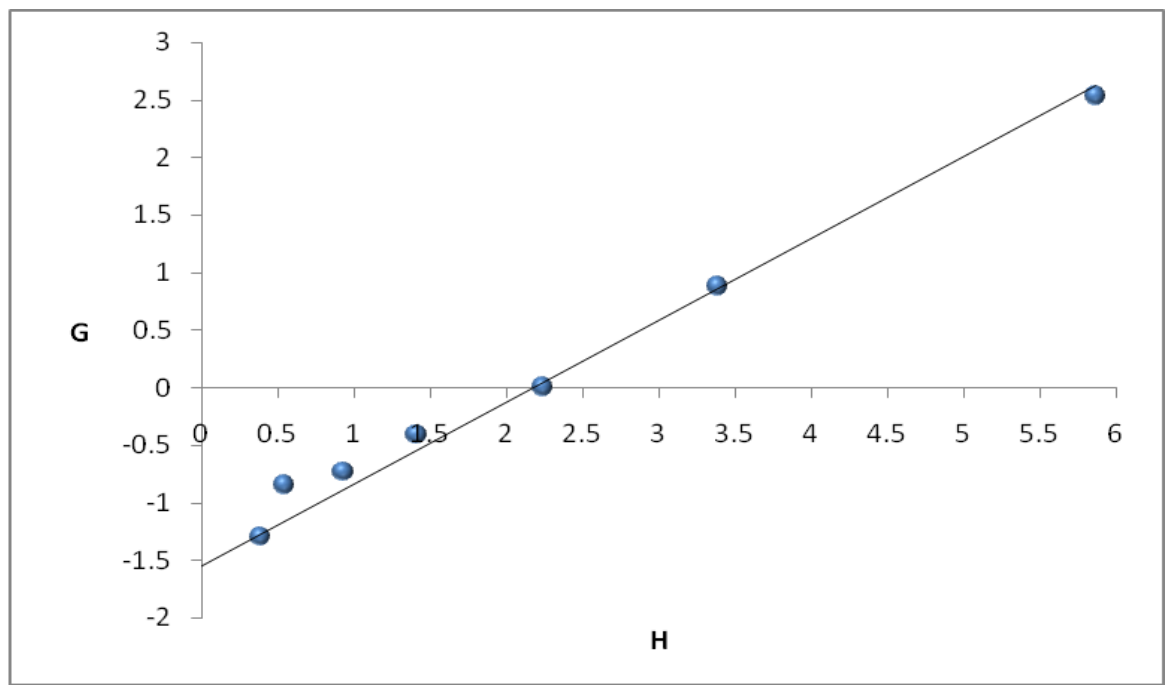

Figure 3 : Fineman-Ross plot for Poly(NCA-co-MACU)

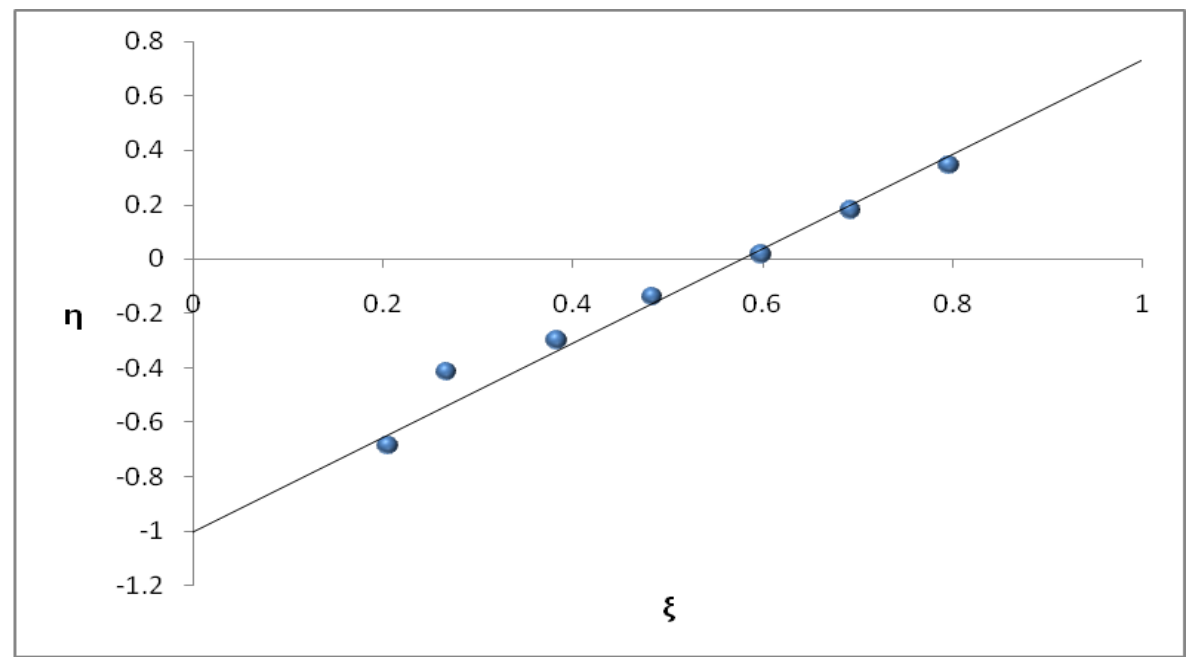

Figure 4 :Kelen-Tudos plot for Poly(NCA-co-MACU) 


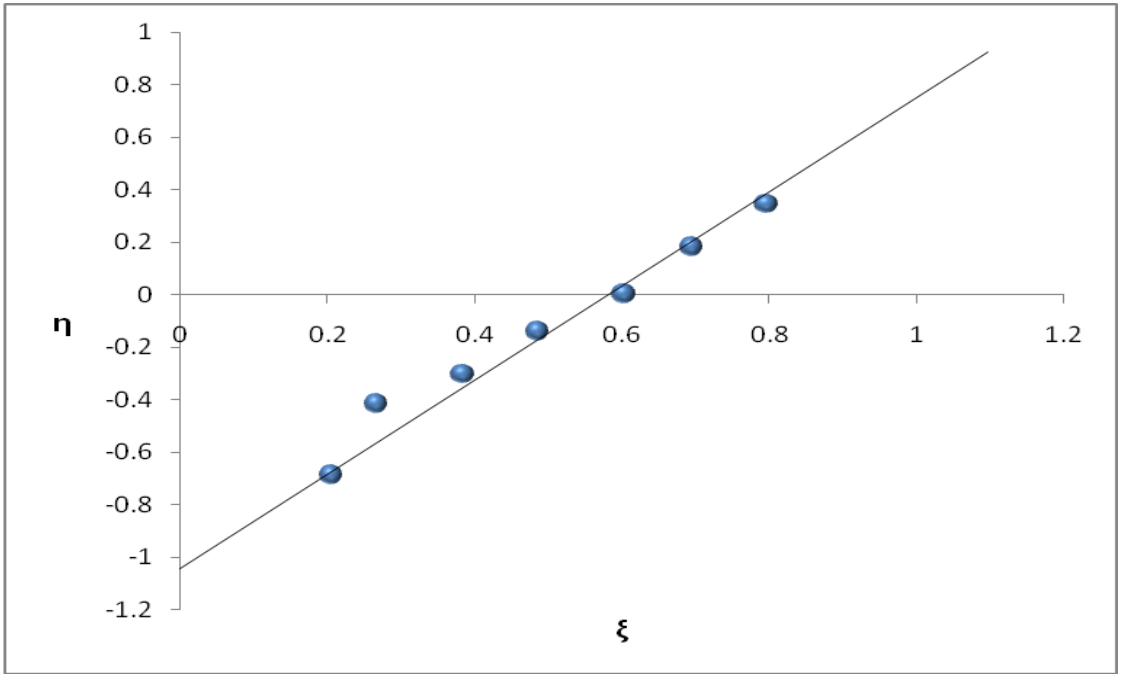

Figure 5: Extended Kelen-Tudos for Poly(NCA-co-MACU)

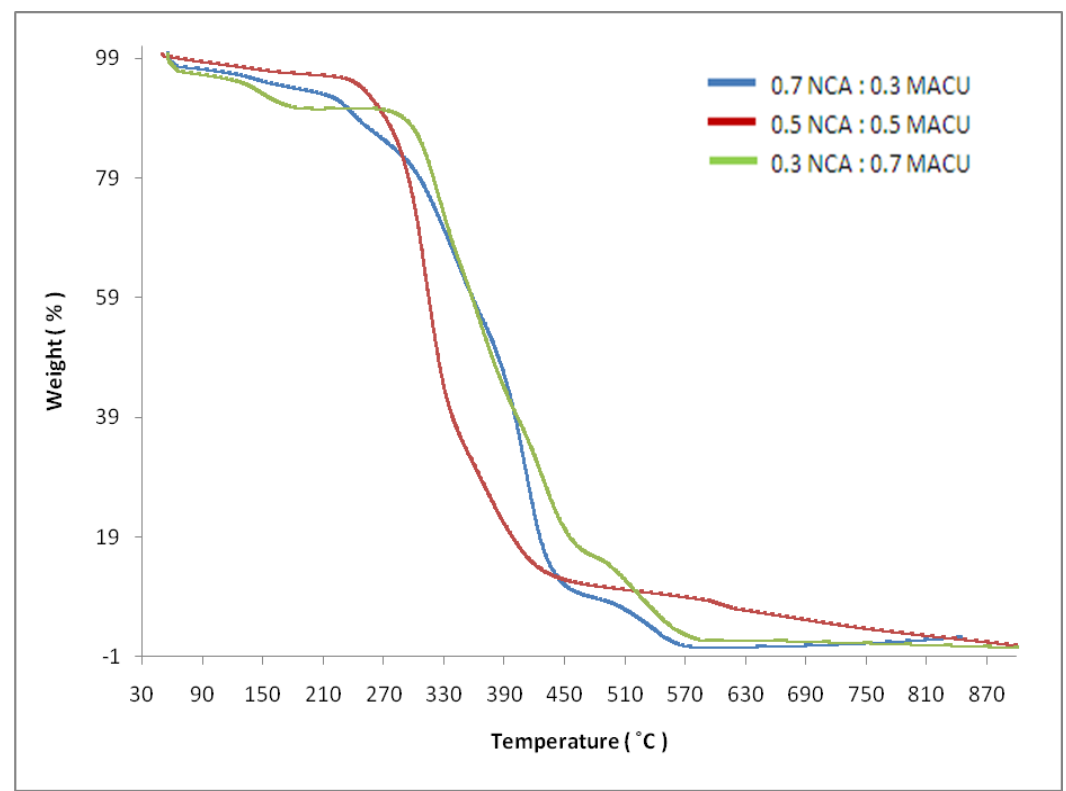

Figure 6 : Thermograms of Poly(NCA-co-MACU) Mole fractions in feed for NCA : $\operatorname{MACU}(0.7: 0.3,0.5: 0.5,0.3: 0.7)$

Table 1: Fineman-Ross and Kelen - Tudos parameters for the Copolymers of Ncyclohexyl acrylamide and MACU

\begin{tabular}{|c|c|c|c|}
\hline$G=F(f-1) / f$ & $H=F^{2} / f$ & -0.6849 & 0.2042 \\
\hline $\mathbf{- 1 . 2 9 6 1}$ & 0.3865 & -0.4143 & 0.2658 \\
\hline $\mathbf{- 0 . 8 4 9 9}$ & 0.5452 & -0.2996 & 0.3823 \\
\hline $\mathbf{- 0 . 7 3 0 4}$ & 0.9321 & -0.1401 & 0.4833 \\
\hline $\mathbf{- 0 . 4 0 8 6}$ & 1.4086 & 0.017 & 0.598 \\
\hline $\mathbf{0 . 0 0 6 5}$ & 2.2401 & 0.1802 & 0.6921 \\
\hline $\mathbf{0 . 8 8 1 8}$ & 3.3857 & 0.3436 & 0.7957 \\
\hline
\end{tabular}

$\alpha=\sqrt{H_{\min \cdot} \cdot H_{\max }}=1.5059$ 
Table 2 : Extended Kelen-Tudos parameters for copolymers of NCA and MACU

\begin{tabular}{|c|c|c|c|c|c|c|c|}
\hline NCA : & $\zeta_{2}$ & $\zeta_{1}$ & $\mathbf{Z}$ & $\mathbf{F}$ & G & $\eta=G /(\alpha+F)$ & $\xi=F /(\alpha+F)$ \\
\hline MACU & & & & & & & \\
\hline $0.2: 0.8$ & 3.4658 & 2.2417 & 0.6494 & 0.3834 & -1.2909 & -0.6875 & 0.2041 \\
\hline $0.3: 0.7$ & 3.1439 & 2.4621 & 0.7866 & 0.5404 & -0.8461 & -0.4158 & 0.2656 \\
\hline $0.4: 0.6$ & 3.2746 & 2.3433 & 0.7179 & 0.9261 & -0.7336 & -0.3031 & 0.3826 \\
\hline $0.5: 0.5$ & 3.2650 & 2.3178 & 0.7104 & 1.4067 & -0.4083 & -0.1407 & 0.4849 \\
\hline $0.6: 0.4$ & 3.3339 & 2.2323 & 0.6671 & 2.2569 & .0065 & 0.0017 & 0.6017 \\
\hline $0.7: 0.3$ & 3.3116 & 2.2819 & 0.6889 & 3.3873 & 0.8819 & 0.1807 & 0.6939 \\
\hline $0.8: 0.2$ & 3.3658 & 2.2947 & 0.6843 & 5.8238 & 2.5239 & 0.3448 & 0.7958 \\
\hline Where, $\mu=$ & $=1.594$ & $\zeta_{2}=w(\mu$ & $-x) /(\mu+y$ & $; \zeta_{1}=\zeta_{2}($ & x) $; z=\log$ & $\left.1-\zeta_{1}\right) / \log (1-$ & \\
\hline$: \alpha=\sqrt{H_{\text {min }}}$ & $\overline{a x}=1.4$ & & & & & & \\
\hline Table 3: & eriz & paran & for & NC & and & $\mathbf{U}(\mathbf{r}$ & vmer \\
\hline & hods & & $\mathbf{r} 1$ & & $\mathbf{r}_{2}$ & & r1.r2 \\
\hline & n-Ross & & 0.7 & & 1.55 & & 1.10 \\
\hline & Tudos & & 0.7 & & 1.51 & & 1.10 \\
\hline Extenc & Eelen-Tt & & 0.7 & & 1.55 & & 1.14 \\
\hline
\end{tabular}

Table 4 : Mean sequence lengths in ( NCA-co-MACU)

\begin{tabular}{|c|c|c|c|c|}
\hline $\begin{array}{l}\text { Mole fraction } \\
\text { of } M A C U \text { in } \\
\text { feed } M_{2}\end{array}$ & $l_{1}$ & $\mathbf{I}_{2}$ & $l_{1}: l_{2}$ & Distribution \\
\hline 0.8 & 1.18 & 7.16 & $1: 7$ & $\mathbf{N}(\mathbf{M})_{7} \mathbf{N}$ \\
\hline 0.7 & 1.31 & 4.59 & $1: 5$ & NMMMMMN \\
\hline 0.6 & 1.49 & 3.31 & $1: 3$ & NMMMN \\
\hline 0.5 & 1.73 & 2.54 & $2: 3$ & NNMMMNN \\
\hline
\end{tabular}




\begin{tabular}{|l|l|l|l|l|}
\hline 0.4 & 2.095 & 2.02 & $2: 2$ & NNMMNN \\
\hline 0.3 & 2.7 & 1.66 & $3: 2$ & NNNMMMM \\
\hline 0.2 & 3.92 & 1.38 & $4: 1$ & NNNNMNNNN \\
\hline
\end{tabular}

Table 5 : TGA data for Poly(NCA-co-MACU)

\begin{tabular}{|c|c|c|c|c|c|c|c|c|c|}
$\begin{array}{c}\text { Mole } \\
\text { fraction of } \\
\begin{array}{c}\text { NPAM in } \\
\text { feed }\end{array}\end{array}$ & Initial & $\begin{array}{c}\text { Stage- } \\
\mathbf{1}\end{array}$ & Stage-2 & Stage-3 & IDT & $\mathbf{T}_{1}$ & $\mathbf{T}_{2}$ & $\mathbf{T}_{\mathrm{f}}$ & $\mathbf{T}_{\mathrm{g}}{ }^{\circ} \mathbf{C}$ \\
\hline $\mathbf{0 . 3}$ & 6.43 & 37.05 & 47.35 & 8.41 & 200 & 365 & 475 & 600 & 112.44 \\
\hline $\mathbf{0 . 5}$ & 3.20 & 63.86 & 22.02 & 9.57 & 200 & 355 & 500 & 900 & 107.63 \\
\hline $\mathbf{0 . 7}$ & 9.06 & 74.71 & 14.36 & & 250 & 475 & 600 & & - \\
\hline Poly NCA & & & & & & & & & 79.2 \\
\hline
\end{tabular}

IDT - Initial Decomposition Temperature in ${ }^{\circ} \mathrm{C} ; \mathrm{T}_{1}$ - Decomposition at stage 1 $\mathrm{T}_{2}$ - Decomposition at stage $2 ; \mathrm{T}_{\mathrm{f}}$ - Final Decomposition $; \mathrm{T}_{\mathrm{g}}$ - Glass Transition Temperature

\section{Antimicrobial Activity of poly (NCA-co- MACU)}

Antimicrobial analysis was carried out by well diffusion method [14, 15] against various bacteria and fungi. Antimicrobial activity was evaluated by measuring the diameter of the zone of inhibition in against the test microorganisms. DMSO was used as solvent control. Ciproflaxacin is used as reference antibacterial agent. Amphotericin B is used as reference antifungal agent. It is observed from the results that both antibacterial and antifungal activity is maximum. The inhibiting activity is found to be more than that of the standard. The antimicrobial activities are shown in Figure 7 and 8 and the zone of inhibition values are given in Table-6and 7. It also showed good antimicrobial activities against selected microorganism. In the 50:50 mole \% containing copolymers showed more antibacterial and antifungal activities than the Ciproflaxacin, Amphotericin Drugs.

Table 6: Antibacterial activity of poly (NCA-co-MACU)

\begin{tabular}{|c|c|c|c|c|}
\hline SI.No & Copolymers & $\begin{array}{l}\text { Escherichia } \\
\text { coli }\end{array}$ & Salmonella typhi & Bacillus cereus \\
\hline 1. & $0.3 \mathrm{NCA}: 0.7 \mathrm{MACU}$ & $19 \mathrm{~mm}$ & $20 \mathrm{~mm}$ & $30 \mathrm{~mm}$ \\
\hline 2. & $0.5 \mathrm{NCA}: 0.5 \mathrm{MACU}$ & $20 \mathrm{~mm}$ & $27 \mathrm{~mm}$ & $40 \mathrm{~mm}$ \\
\hline 3. & 0.7 NCA:0.3 MACU & $12 \mathrm{~mm}$ & $18 \mathrm{~mm}$ & $16 \mathrm{~mm}$ \\
\hline 4. & Ciproflaxacin & $10 \mathrm{~mm}$ & $24 \mathrm{~mm}$ & $32 \mathrm{~mm}$ \\
\hline
\end{tabular}


Table 7: Antifungal activity of poly (NCA-co-MACU)

\begin{tabular}{|c|c|c|c|c|}
\hline Sl.No & Compounds & $\begin{array}{l}\text { Aspergillus } \\
\text { niger }\end{array}$ & Candida albicans & $\begin{array}{l}\text { Candida } \\
\text { tropicalis }\end{array}$ \\
\hline 1. & $0.3 \mathrm{NCA}: 0.7 \mathrm{MACU}$ & $02 \mathrm{~mm}$ & $18 \mathrm{~mm}$ & $16 \mathrm{~mm}$ \\
\hline 2. & $0.5 \mathrm{NCA}: 0.5 \mathrm{MACU}$ & $03 \mathrm{~mm}$ & $32 \mathrm{~mm}$ & $28 \mathrm{~mm}$ \\
\hline 3. & 0.7 NCA:0.3 MACU & $02 \mathrm{~mm}$ & $14 \mathrm{~mm}$ & $11 \mathrm{~mm}$ \\
\hline 4. & Amphotericin B & $26 \mathrm{~mm}$ & $24 \mathrm{~mm}$ & $30 \mathrm{~mm}$ \\
\hline
\end{tabular}

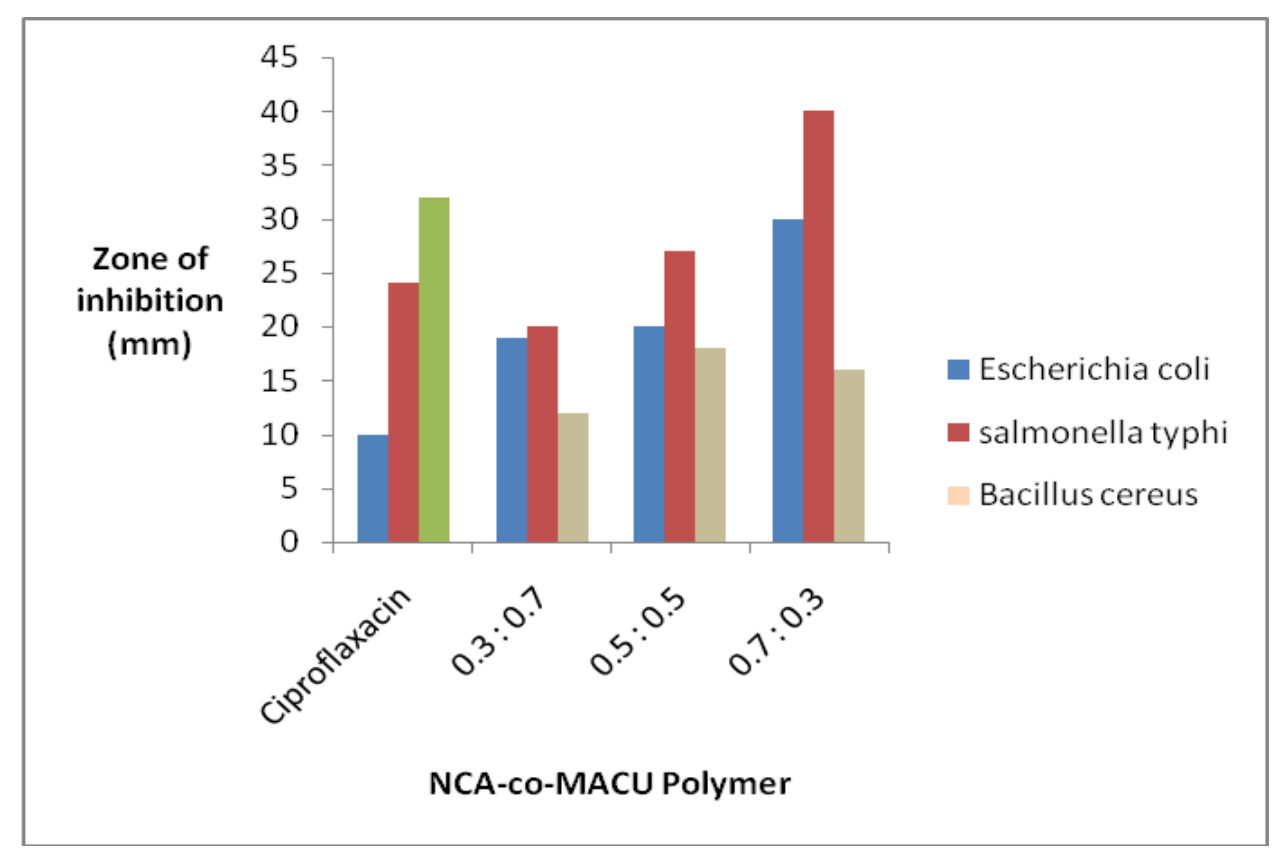

Figure 7: Comparison of Zone of inhibition of Poly(NCA-co-MACU)with different bacteria

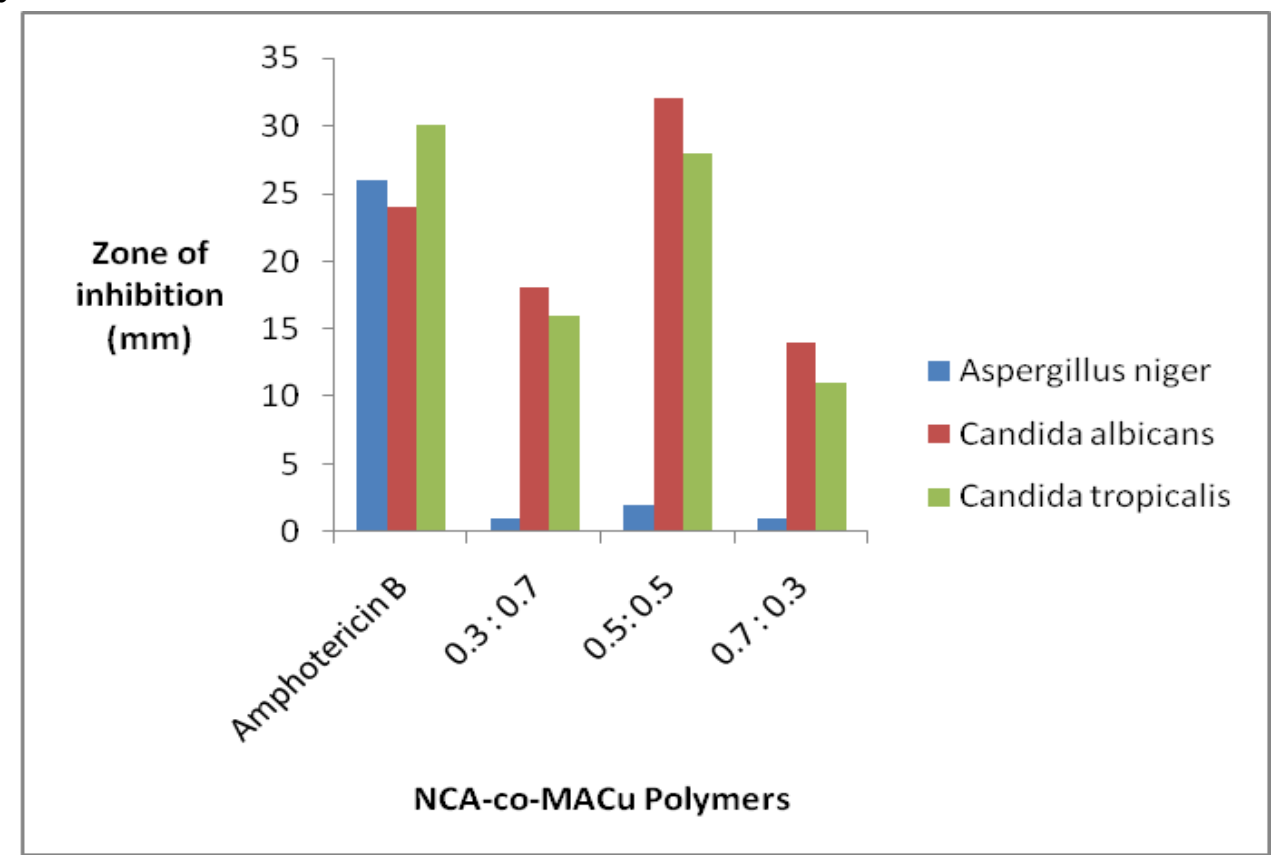

Figure 8: Comparison of Zone of inhibition of Poly(NCA-co-MACU)with different fungi Conclusions 
N-cylohexylacrylamide (NCA) and 7-methacryloyloxy-4-methylcoumarin (MACU) copolymers were prepared by free radical polymerization. The copolymer compositions were determined by ${ }^{1} \mathrm{H}-\mathrm{NMR}$ analysis. The reactivity ratios of monomers) $\left(\mathrm{r} 1=0.71\right.$ and $\mathrm{r}_{2}=1.55$ )$,\left(\mathrm{r} 1=0.73\right.$ and $\left.\mathrm{r}_{2}=1.51\right),(\mathrm{r} 1=0.74$ and $\mathrm{r} 2=1.55)$ were determined by Fineman-Ross $(\mathrm{FR})$ Kelen-Tudos (KT) and Exetented Kelen -Tudos respectively, The $\mathbf{r}_{1} \cdot r_{2}=1.10$ indicated the formation of random copolymers. $\mathrm{T}_{\mathrm{g}}$ found to increasing with increasing of feed content of MACU. The antimicrobial studies showed that the copolymers are active against both Bacteria and Fungi.

\section{References}

1. J.D.Schroeder, J.C.Scales, US Patent C 5174, Chem.Abst., 136 (22), 345880 k (2002).

2. Y.Edeole, J.Y. Barbin, Chem.Abst., 136 (22), 341547 j(2002).

3. Chitra R, Jeyanthi P and Pazhanisamy P, Int.J. ChemTech Res., 2010, 2(4), 1871-1880.

4. Chitra R, Kayalvizhi E, Jeyanthi $P$ and Pazhanisamy P, Rasayan Journal of Chemistry,

5. 2013, 6(1), 80-88.

6. R.Chitra, P.Pazhanisamy, Int.J of Applied Research, 4(1), 561-569, (2014).

7. R.Chitra,E.Kayalvizhi, P.Jeyanthi, P.Pazhanisamy, Chem.Sci.Transactions, 3(2), 722 -

8. 730, (2014).

9. M.Fineman and S.D.Ross, J. Polym. Sci., (1950).5(2), 259

10. T.Kelen and F. Tudos, J. Macro. Sci. Chem., A 9, 1(1975).

11. T.Kelen and F.Tudos, React.Kinet.Catal.Lett., 2(4), 439 (1975).

12. P. Pazhanisamy and B. S. R. Reddy., Express Polymer Letters, 1(11),740-747 (2007).

13. 11. H. J Patel, M. G Patel, R. J Patel, K. H Patel and R. M Patel, Iranian Polymer Journal, 17(8), 635-644 (2008).

14. [14] T.Kelen and F.Tudos, React.Kinet.Catal.Lett., 1(4), 487 (1974).

15. [15] T.Kelen and F.Tudos, J.Macromol.Sci.Chem., A9, 1 (1975). 